\title{
ANALYSIS ON QUALITY OF LIFE OF PATIENTS WITH OSTEOARTHROSIS UNDERGOING TOTAL HIP ARTHROPLASTY
}

Elmano de Araújo Loures' ${ }^{1}$, Isabel Cristina Gonçalves Leite ${ }^{2}$

\section{ABSTRACT}

Objective: The aim of the study was to evaluate the health-related quality of life among patients affected by hip osteoarthrosis who were treated by means of total hip arthroplasty. Methods: A cohort of 38 patients operated by a single surgeon in a regional referential teaching hospital during the year 2010 was prospectively studied and followed up for at least six months until they had achieved satisfactory rehabilitation. Each patient gave responses to the SF-36 form immediately before the operation and six months later and the Harris Hip Score was obtained at the same time. The pre and postoperative results were analyzed and compared with the literature. Results: The pre and postoperative SF-36 results were as follows: physical function: 13.4-53.7; role physical: 9.21-48.0; body pain: 23.1-62.6; general health: 54.2-71.3; vitality: 40.3-69.9; social function: 40.8-74.3; role emotional: 23.7-64.9; and mental health: 52.6-
80.4. The Harris Hip Score went from 36.1 to 92.1, on average. All the results were statistically significant $(\mathrm{p}<0.001)$. Conclusions: The combination of two scales was shown to be valuable in identifying bias and gave greater reliability for understanding the different variables. The study showed that there was a significant improvement in health-related quality of life among patients affected by osteoarthrosis of different etiologies who underwent total hip arthroplasty. Health-related quality of life evaluations cannot replace clinical evaluations provided by specific instruments and physicians' experience but can add important data through giving value to patients' sets of expectations regarding medical treatment. Moreover, such evaluations can be considered to be an efficient tool for analyzing the outcomes from total hip arthroplasty.

Keywords - Hip; Osteoarthritis; Arthroplasty, Replacement, Hip; Quality of Life

\section{INTRODUCTION}

Total hip replacement is a surgical procedure that has been widely used over recent decades. It is an intervention that causes a dramatic improvement in the individual's functional state and also in his quality of life, especially in cases of severe degenerative arthritis. However, there are important variations in the clinical decisions in different environments and circumstances, and in interpreting the results, analyzing the cost of care and identifying over or under-indication of procedures like joint replacement ${ }^{(1)}$.

Health-related quality of life was defined by the World Health Organization (WHO) as a multidimensional model that includes physical, material, social and emotional wellbeing, as well as individual deve- lopment and daily activities ${ }^{(2)}$. It is a complex concept that requires specially developed instruments for evaluating the changes in quality of life that occur subsequent to medical treatment. The physical and functional characteristics of each individual treated with total hip replacement necessitate effective measured made using validated instruments that are capable of furnishing observers with reliable data.

Obtaining precise results from patients undergoing surgical interventions is a task that is considered to be difficult. Traditionally, until a decade ago, the outcomes from joint replacement were evaluated solely through analyzing the morbidity, mortality, implant wear and operative complication rates. The modern approach towards the results from orthopedic

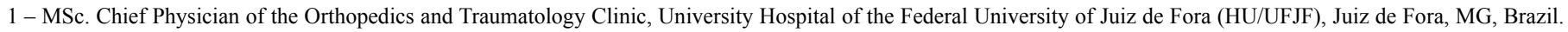
2 - PhD. Adjunct Professor in the School of Medicine, Federal University of Juiz de Fora (UFJF), Juiz de Fora, MG, Brazil.

Work performed at the Orthopedics and Traumatology Clinic, University Hospital of the Federal University of Juiz de Fora (HU/UFJF).

Correspondence: Av. Olegário Maciel 297/1101, Santa Helena, 36015-350 Juiz de Fora, MG. E-mail: loures.elmano@oi.com.br

Work received for publication: May 26, 2011; accepted for publication: July 20, 2011.
}

The authors declare that there was no conflict of interest in conducting this work 
joint replacement surgery is no longer based only on success or failure of the implant: the focus is directed towards patient satisfaction and the level of quality of life attained. In this, the comorbidities need to be taken into consideration and specific measures for the joint need to be associated, in relation to the generic components through which individuals' general status is analyzed ${ }^{(3)}$. Thus, it has become clear that for a procedure that ultimately aims to improve individuals' quality of life, measurement of these indices becomes necessary in order to achieve complete comprehension of the effects from this intervention ${ }^{(4)}$.

As the population's life expectancy has increased, the number of joint replacements has followed the same trend. Despite the high cost of these procedures, they are among the most effective in terms of benefits. Moreover, trustworthy parameters that provide clinical guidelines for indications and establish secure criteria at the time of evaluating the results are increasingly valued, especially when applied to a large population $^{(5)}$. The most recent studies in the literature delineate a growing movement towards placing value on gathering results self-reported by patients who have undergone total hip replacement, and towards seeking methods of greater applicability and reliability ${ }^{(6)}$.

Many variables influence health-related qualityof-life scores and also individuals' expectations regarding medical procedures and their results. A study by Ackerman et $a l^{(7)}$ found that in an Australian population, the female group of lower socioeconomic level and with prolonged waiting times for surgery was more likely to have low scores, which were associated with high levels of psychological stress, abrupt reduction of functional level and also a high potential morbidity rate. Among such patients, both the objective measurements of the results and individuals' perceptions of the postsurgical effects were clearly affected $^{(7)}$. This set of data can only be correctly quantified through quality-of-life measurements, and several studies have highlighted their importance and applicability as reliable and useful clinical indicators for defining disease management strategies ${ }^{(5,7)}$.

The primary objective of the present study was to ascertain the health-related quality-of-life variations among osteoarthrotic patients who underwent total hip replacement, using a general instrument and a specific indicator for the hip joint, and to compare the results with the literature.

\section{MATERIAL AND METHODS}

Approval for this study was obtained from our institution's Research Ethics Committee, under the number CEP 0161/2009, and all the patients gave consent for their participation in the present study, before the surgical procedure.

Between January and December 2010, out of an initial sample of 40 individuals, 38 patients who had been operated consecutively by the same surgeon were selected. These patients were followed up for a minimum of six months and completed a rehabilitation protocol in an observational applied clinical study of prospective cohort type. The two individuals who were excluded presented unfavorable clinical intercurrences (coronary diseases) during the period of preparing and waiting for the intervention. Thirty-five of them received a hybrid implant with the MD- ${ }^{\circledR}$ acetabular component, a spray coating of plasma titanium and a polished cemented stem, made in Brazil. Only three osteopenic patients received cemented acetabular components. All the acetabular components used had a rim raised by $10^{\circ}$. Heads of $28 \mathrm{~mm}$ were used in all the patients, except for one case of hip developmental dysplasia that received an interchangeable head of 22 $\mathrm{mm}$ because a small-diameter dome was used. A right lateral surgical access was used in all the cases.

The inclusion criteria were as follows: severe radiological hip osteoarthrosis (grades III and IV), according to the Kellgren and Lawrence classification $^{(8)}$; Harris Hip Score (HHS) ${ }^{(9)}$ lower than 60 points (significant pain and incapacity); age group over 21 years; indication for unilateral surgery with monoarticular symptoms; no other previous joint replacement procedure undergone; and satisfactory clinical conditions with a low or intermediate surgical risk, i.e. with compensated comorbidities at the time of hospital admission.

The exclusion criteria were as follows: presentation of neurological deficits, cognitive deficits and/or significant psychological disorders that made it impossible to comprehend and answer the questionnaires, or to follow the therapeutic process and subsequent physical rehabilitation adequately; morbid obesity and any local, distant or systemic active infection; survival for less than six months after the intervention; reoperation due to early implant failure, i.e. within six months of the intervention, for any reason; and revision surgery on total hip arthroplasty. 
The profile of the sample studied is described in Figures 1 and 2, with regard to etiology and age group.

The patients gave responses to the Medical Outcomes Study SF-36 questionnaire ${ }^{(10,11)}$, which provides a generic quality-of-life measurement and was validated for Brazil by Ciconelli et $a l^{(10)}$. It consists of a scale of eight domains of functional health and wellbeing, along with summary psychometric measurements of physical and mental health. The SF-36 is frequently used as a reference point for other tests ${ }^{(12,13)}$. The final score is proportional to individual wellbeing ${ }^{(14,15)}$.

The Harris Hip Score (HHS) is a specific assessment instrument that was designed to evaluate the functional state of the coxofemoral joint. It is an objective scale that is used worldwide. Its maximum score is 100 points and it evaluates pain, function, deformity and range of motion, such that pain and function have greater weight. It is a system of proven reproducibility ${ }^{(9)}$.

The SF-36 questionnaire and the HHS were applied to the selected patients before the operation and

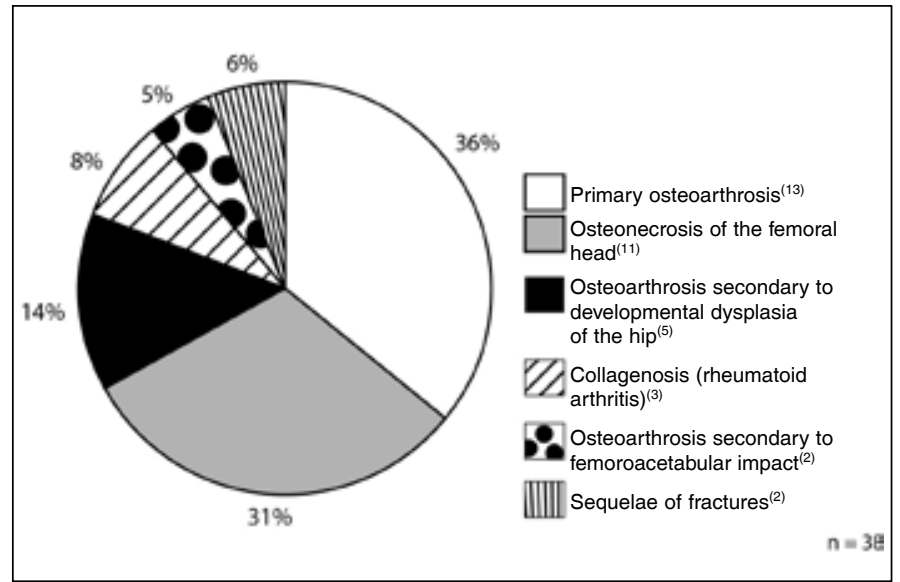

Figure 1 - Etiological distribution of the sample studied (Juiz de Fora, MG, 2011).

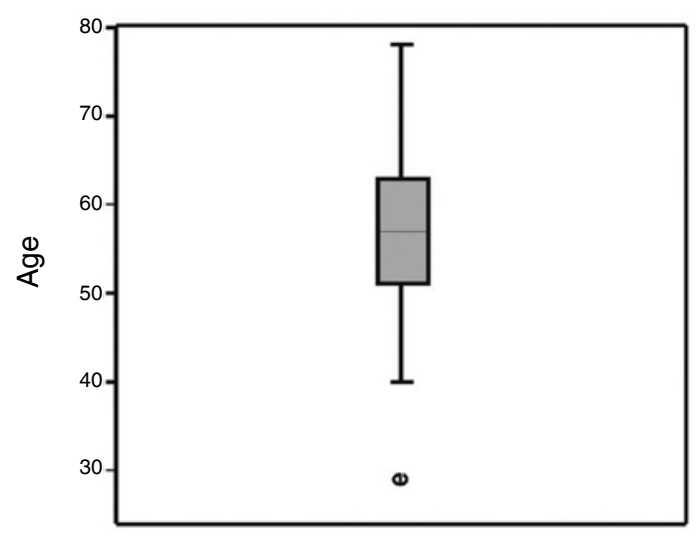

Figure 2 - Age group of the sample studied (Juiz de Fora, MG, 2011). after six months of evolution, i.e. when the basic rehabilitation period had been completed. All the results were compared with the literature.

The standard deviation was calculated for each item investigated, both before and after the operation. The Mann-Whitney test was used for paired comparisons when the data were normally distributed and the Wilcoxon test was used for nonparametric data. The significance level was set at $\mathrm{p}<0.05$. The data analysis was developed using SPSS (Statistical Package for the Social Sciences), version 15.0 (Chicago, IL, USA).

The measurements on individuals' satisfaction with the procedure were made blindly and were obtained by capacitated independent observers who were not members of the medical care team. The patients were offered a choice of four levels of personal satisfaction.

\section{RESULTS}

No cases of infection, intraoperative fracture, deep vein thrombosis or any local or general clinical complications of postoperative relevance were recorded. The only complication was one case of neuropraxia of the fibular branch of the sciatic nerve, in a patient with developmental dysplasia of the hip and stretching of $3 \mathrm{~cm}$, who achieved partial recovery after six months of evolution and subtotal recovery after nine months. On a postoperative control radiograph produced 45 days after the operation, detachment of a small fragment from the greater trochanter was observed in two osteopenic cases, but both cases evolved to bone consolidation without any clinical repercussions. The acetabular component was seen to have a high inclination angle $\left(>55^{\circ}\right)$ in three cases $\left(56^{\circ}, 59^{\circ}\right.$ and $60^{\circ}$ ), without compromising joint stability. No cases of dislocation were observed in this series. All the implants were considered to have become fixed, as seen on the final radiographic assessment.

The results from the SF-36 and HHS are shown in Table 1, and the results from the personal satisfaction assessment are shown in Table 2.

The variables associated with quality of life in the initial and final HHS, with mean values and statistical significance, are demonstrated in Tables 3 and 4.

The characteristics of the sample according to the independent variables are shown in Table 5.

The variables associated with quality of life in the nine initial and final SF-36 scores, with mean values and statistical significance, are demonstrated in Tables 6 and 7. 
Table 1 - Mean scores for the eight domains that make up the SF-36 and for the Harris Hip Score, with statistical significance ( $p$-value), 2011.

\begin{tabular}{c|c|c|c}
\hline \multirow{2}{*}{ Variables } & $\begin{array}{c}\text { Before } \\
\text { operation }\end{array}$ & $\begin{array}{c}\text { After } \\
\text { operation }\end{array}$ & \multirow{2}{*}{$\mathbf{p}$} \\
\cline { 2 - 3 } Mean (sd) & Mean (sd) & \\
\hline SF-36 & & & \\
\hline $\begin{array}{c}\text { Functional capacity } \\
\text { Limitation due to physical } \\
\text { aspects }\end{array}$ & $13.40(14.9)$ & $53.70(27.3)$ & $<0.010$ \\
\hline Pain & $9.21(22.1)$ & $48.00(40.4)$ & $<0.001$ \\
\hline General state of health & $23.10(18.2)$ & $62.60(24.8)$ & $<0.002$ \\
\hline Vitality & $40.20(23.0)$ & $71.30(22.3)$ & $<0.001$ \\
\hline Social aspects & $40.80(26.2)$ & $69.90(21.5)$ & $<0.001$ \\
\hline Emotional aspects & $23.70(36.3)$ & $64.90(37.1)$ & $<0.001$ \\
\hline Mental health & $52.60(27.2)$ & $80.40(17.2)$ & $<0.001$ \\
\hline HHS & $36.10(15.9)$ & $92.10(5.6)$ & $<0.001$ \\
\hline
\end{tabular}

Table 2 - Self-perceived general state of health and degree of postoperative satisfaction, 2011.

\begin{tabular}{c|c|c}
\hline Variables & N & $\%$ \\
\hline Self-perceived general state of health (SF-36) & & \\
\hline Much better now than one year ago & 24 & 63.2 \\
\hline A bit better now than one year ago & 10 & 23.3 \\
\hline Almost the same as one year ago & 4 & 10.5 \\
\hline Degree of satisfaction with the surgery & & \\
\hline Very satisfied & 23 & 60.5 \\
\hline Satisfied & 13 & 34.2 \\
\hline Reasonably satisfied & 2 & 5.3 \\
\hline
\end{tabular}

Table 3 - Variables associated with quality of life in the total score for the initial HHS: mean score and statistical significance ( $p$-value), 2011.

\begin{tabular}{c|c|c}
\hline \multirow{2}{*}{ Variables } & \multicolumn{2}{|c}{ Total } \\
\cline { 2 - 3 } & Mean (sd) & $\boldsymbol{p}$ \\
\hline Age & $33.4(1.5)$ & 0.17 \\
From 20 to 60 years & $40.7(1.6)$ & \\
From 61 to 99 years & $34.5(1.4)$ & 0.66 \\
\hline Ethnicity & $38.2(1.8)$ & \\
White & & \\
Others & $32.9(1.7)$ & 0.38 \\
Retired & $37.7(1.5)$ & \\
Yes & & \\
No & $32.4(1.4)$ & \\
\hline Needing help & $49.7(1.2)$ & 0.01 \\
Yes & & \\
No & $38.5(1.1)$ & \\
\hline Receiving benefit & $35.5(1.6)$ & \\
Yes & & \\
No & $37.2(1.6)$ & \\
Income & $34.0(1.1)$ & \\
1 to 2 minimum salaries & $32.8(2.0)$ & \\
2 to 3 minimum salaries & & \\
More than 3 minimum & & \\
salaries & & \\
\hline
\end{tabular}

Table 4 - Variables associated with quality of life in the total score for the final HHS: mean score and statistical significance ( $p$-value), 2011

\begin{tabular}{c|c|c}
\hline \multirow{2}{*}{ Variables } & \multicolumn{2}{|c}{ Total } \\
\cline { 2 - 3 } & Mean (sd) & $\mathbf{p}$ \\
\hline Age & $92.4(5.0)$ & 0.60 \\
From 20 to 60 years & $91.4(6.6)$ & \\
\hline Ethnicity & & \\
White & $92.1(5.6)$ & 0.62 \\
Others & $91.9(5.7)$ & \\
\hline Retired & & \\
Yes & $93.0(6.1)$ & 0.46 \\
No & $91.5(5.4)$ & \\
\hline Needing help & & \\
Yes & $91.9(5.7)$ & 0.98 \\
No & $92.2(5.5)$ & 0.20 \\
\hline Yes & $89.6(5.0)$ & \\
No & $92.6(5.7)$ & \\
\hline Income & $92.0(5.9)$ & \\
\hline 1 to 2 minimum salaries & $91.3(5.8)$ & \\
2 to 3 minimum salaries & $93.2(4.1)$ & \\
More than 3 minimum & & \\
salaries & &
\end{tabular}

\section{DISCUSSION}

In the present study, $100 \%$ of the items appearing in the SF-36 questionnaire were obtained, which should be compared with the results in the literature, where up to $5.3 \%$ of all responses were incomplete and/or unanswered for a variety of reasons ${ }^{(16,17)}$. The assistance provided to the patients during the process of answering the questions may explain the high completion rate obtained.

The measurements on the patients' degree of satisfaction with the procedure were done blindly by an independent observer, and this had the aim of attenuating the information bias.

Most of the patients selected for total hip replacement arthroplasty were diagnosed as presenting primary osteoarthrosis (Figure 1).

A study by Tellini et al ${ }^{(18)}$ indicated that lower mean age and consequent lower prevalence of comorbidities was associated with higher values for the postoperative indices measured by the SF-36 $6^{(18,19)}$. However, these same individuals demonstrated lower values for the preoperative mental health score, thus inferring that this younger group had a lower capacity to deal with functional limitations, in comparison with older patients. These authors identified an information bias (recall bias) through observing that recently rehabilitated patients tended to overestimate their current physical state, compared with their preoperative state, when the clinical situation and its psychological effects were presumably at their worst level, given that these 
Table 5 - Characteristics of the sample according to independent variables, 2011.

\begin{tabular}{|c|c|c|}
\hline Variables & $\mathbf{N}$ & $\%$ \\
\hline $\begin{array}{c}\text { Sex } \\
\text { Male } \\
\text { Female } \\
\end{array}$ & $\begin{array}{l}21 \\
17 \\
\end{array}$ & $\begin{array}{l}55.3 \\
44.7 \\
\end{array}$ \\
\hline $\begin{array}{c}\text { Age } \\
\text { Up to } 60 \text { years } \\
\text { More than } 60 \text { years }\end{array}$ & $\begin{array}{l}24 \\
14 \\
\end{array}$ & $\begin{array}{l}63.2 \\
36.8\end{array}$ \\
\hline $\begin{array}{c}\text { Schooling Illiterate } \\
1 \text { to } 4 \text { years } \\
5 \text { to } 8 \text { years } \\
9 \text { to } 10 \text { years } \\
11 \text { or more }\end{array}$ & $\begin{array}{c}4 \\
21 \\
7 \\
6\end{array}$ & $\begin{array}{l}10.5 \\
55.3 \\
18.4 \\
15.8\end{array}$ \\
\hline $\begin{array}{l}\text { Ethnicity } \\
\text { White } \\
\text { Black } \\
\text { Mixed } \\
\end{array}$ & $\begin{array}{c}22 \\
10 \\
6\end{array}$ & $\begin{array}{l}57.9 \\
26.3 \\
15.8\end{array}$ \\
\hline $\begin{array}{c}\text { Location of home } \\
\text { Municipality where study was conducted } \\
\text { Microregion } \\
\text { Macroregion }\end{array}$ & $\begin{array}{l}29 \\
8 \\
1\end{array}$ & $\begin{array}{l}73.3 \\
21.1 \\
2.6\end{array}$ \\
\hline $\begin{array}{c}\begin{array}{c}\text { Domestic arrangements } \\
\text { Living with companion } \\
\text { Living alone }\end{array} \\
\end{array}$ & $\begin{array}{c}31 \\
7 \\
\end{array}$ & $\begin{array}{l}81.6 \\
18.4 \\
\end{array}$ \\
\hline $\begin{array}{c}\text { Needing help } \\
\text { Not needed } \\
\text { Need for domestic activities } \\
\text { Need for personal activities } \\
\text { Need for all daily activities }\end{array}$ & $\begin{array}{l}8 \\
3 \\
17 \\
10\end{array}$ & $\begin{array}{l}21.1 \\
7.9 \\
44.7 \\
26.3\end{array}$ \\
\hline $\begin{array}{c}\text { Retired } \\
\text { Yes } \\
\text { No } \\
\end{array}$ & $\begin{array}{l}13 \\
25 \\
\end{array}$ & $\begin{array}{l}34.2 \\
65.8 \\
\end{array}$ \\
\hline $\begin{array}{c}\text { Occupation } \\
\text { Manual } \\
\text { In home } \\
\text { Technical/administrative } \\
\text { Commercial } \\
\text { Other } \\
\end{array}$ & $\begin{array}{l}25 \\
6 \\
4 \\
2 \\
1\end{array}$ & $\begin{array}{l}65.8 \\
15.8 \\
10.5 \\
5.3 \\
2.6\end{array}$ \\
\hline $\begin{array}{c}\text { Receiving benefit } \\
\text { Yes } \\
\text { No }\end{array}$ & $\begin{array}{c}7 \\
31\end{array}$ & $\begin{array}{l}18.4 \\
81.6\end{array}$ \\
\hline $\begin{array}{c}\text { Income } \\
1 \text { to } 2 \text { minimum salaries } \\
2 \text { to } 3 \text { minimum salaries } \\
\text { More than } 3 \text { minimum salaries }\end{array}$ & $\begin{array}{l}26 \\
7 \\
5\end{array}$ & $\begin{array}{l}68.4 \\
18.4 \\
13.2\end{array}$ \\
\hline $\begin{array}{c}\text { Antecedents of manual work } \\
\text { Yes } \\
\text { No }\end{array}$ & $\begin{array}{l}18 \\
20\end{array}$ & $\begin{array}{l}47.4 \\
52.6\end{array}$ \\
\hline $\begin{array}{c}\text { History of intense sports activities } \\
\text { Yes } \\
\text { No }\end{array}$ & $\begin{array}{c}6 \\
32\end{array}$ & $\begin{array}{l}15.8 \\
84.2\end{array}$ \\
\hline
\end{tabular}

patients presented an SF-36 result that was better than for a healthy control group except on the physical limitation scale. Thus, in considering a younger population, evaluation of social and mental health characteristics is critical. It was observed by some authors that women under the age of 65 years who were affected by chronic diseases suffered more from psychological disorders than did men ${ }^{(20)}$. In a randomized clinical study involving 188 patients who were followed up for three months and 179 for six months, Laupacis et al ${ }^{(21)}$ demonstrated that there was significant evolution of the health-related quality of life that was attained, which was already substantial in the third month of follow-up, especially in terms of physical function, social interaction and general health. However, despite the marked improvement in all the characteristics considered, no equivalent association was seen with regard to the return to work. Factors such as age, educational level, profession and other unidentified factors had a strong influence on this. In the group of the present study, out of the seven individuals whose work capacity was presumably reestablished, only three returned to work before reaching full form. All of these three individuals declared that they were "very satisfied", reached "excellent" Harris Hip Scores, were active, had higher schooling levels, were among the youngest patients and had high expectations prior to surgery.

In our cohort, we observed that four individuals $(10.5 \%)$ showed a clear contradiction between the SF-36 results and the clinical-radiographic assessment,

Table 6 - Variables associated with quality of life, in the nine scores that make up the initial SF-36: mean score and statistical significance ( $p$-value), 2011.

\begin{tabular}{|c|c|c|c|c|c|c|c|c|c|c|c|c|c|c|c|c|c|c|}
\hline \multirow{2}{*}{ Variáveis } & \multicolumn{2}{|c|}{ Function } & \multicolumn{2}{|l|}{ Physical } & \multicolumn{2}{|l|}{ Pain } & \multicolumn{2}{|l|}{ Health } & \multicolumn{2}{|c|}{ Vitality } & \multicolumn{2}{|l|}{ Social } & \multicolumn{2}{|c|}{ Emotional } & \multicolumn{2}{|l|}{ Mental } & \multicolumn{2}{|l|}{ Final } \\
\hline & Mean (sd) & p & Mean (sd) & $\mathbf{p}$ & Mean (sd) & $\mathbf{p}$ & Mean (sd) & $\mathbf{p}$ & Mean (sd) & p & Mean (sd) & $\mathbf{p}$ & Mean (sd) & $\mathbf{p}$ & Mean (sd) & p & Mean (sd) & p \\
\hline Age & & 0.28 & & 0.66 & & 0.20 & & 0.74 & & 0.43 & & 0.26 & & 0.35 & & 0.44 & & 0.61 \\
\hline From 20 to 60 years & $11.6(14.1)$ & & $10.4(23.2)$ & & $20.2(13.7)$ & & $53.2(25.0)$ & & $37.7(27.8)$ & & $37.5(21.8)$ & & $19.4(35.3)$ & & $50.0(28.2)$ & & $4.1(1.0)$ & \\
\hline From 61 to 99 years & $17.1(16.2)$ & & $7.14(20.6)$ & & $28.1(23.8)$ & & $55.7(19.8)$ & & $44.6(23.4)$ & & $46.4(26.1)$ & & $30.9(38.0)$ & & $57.1(25.6)$ & & $4.0(0.8)$ & \\
\hline Ethnicity & & 0.13 & & 0.95 & & 0.11 & & 0.29 & & 0.26 & & 0.50 & & 0.94 & & 0.14 & & 0.13 \\
\hline White & $10.0(14.4)$ & & $9.0(19.7)$ & & $18.7(14.7)$ & & $50.5(23.6)$ & & $35.0(26.9)$ & & $38.0(25.4)$ & & $24.2(37.3)$ & & $45.8(27.2)$ & & $4.32(0.9)$ & \\
\hline Others & $18.7(14.5)$ & & $9.3(25.6)$ & & $29.2(21.0)$ & & $59.1(21.9)$ & & $47.5(24.0)$ & & $44.5(20.9)$ & & $22.9(35.9)$ & & $62.0(24.9)$ & & 3. $8(0.8)$ & \\
\hline Retired & & 0.12 & & 0.49 & & 0.51 & & 0.71 & & 0.23 & & 0.23 & & 0.94 & & 0.16 & & 0.63 \\
\hline Yes & $18.8(18.2)$ & & $5.7(14.9)$ & & $25.8(17.1)$ & & $56.0(20.7)$ & & $47.3(25.4)$ & & $47.1(23.4)$ & & $23.0(34.3)$ & & $61.2(31.2)$ & & 4. $0(1.0)$ & \\
\hline No & $11.0(12.5)$ & & $11.0(25.0)$ & & $21.7(18.8)$ & & $53.1(24.4)$ & & $36.6(26.3)$ & & $37.5(23.3)$ & & $23.9(37.9)$ & & $48.1(24.2)$ & & $4.1(0.8)$ & \\
\hline Needing help & & $<0.01$ & & 0.41 & & 0.16 & & 0.99 & & $<0.01$ & & 0.29 & & 0.47 & & 0.17 & & 0.01 \\
\hline Yes & $10.0(11.8)$ & & $7.5(19.8)$ & & $20.9(17.1)$ & & $54.1(22.6)$ & & $34.3(22.2)$ & & $38.3(23.8)$ & & $21.1(34.4)$ & & $49.3(26.0)$ & & $4.3(0.7)$ & \\
\hline No & $27.5(18.1)$ & & $15.6(29.6)$ & & $31.5(20.7)$ & & $54.3(26.1)$ & & $62.5(29.2)$ & & $50.0(21.1)$ & & $33.3(43.6)$ & & $65.0(29.4)$ & & $3.3(1.1)$ & \\
\hline Receiving benefit & & 0.15 & & 0.46 & & 0.58 & & 0.72 & & 0.22 & & 0.19 & & 0.05 & & 0.54 & & 0.32 \\
\hline Yes & $6.4(4.7)$ & & $3.5(9.4)$ & & $19.7(11.2)$ & & $51.2(34.9)$ & & $29.2(18.1)$ & & $30.3(12.1)$ & & $0.0(0.0)$ & & $46.8(22.3)$ & & $4.4(0.7)$ & \\
\hline No & $15.3(16.0)$ & & $10.4(23.9)$ & & $23.9(19.4)$ & & $54.8(20.2)$ & & $42.7(27.3)$ & & $43.1(24.9)$ & & $29.0(38.2)$ & & $53.9(28.3)$ & & $4.0(0.9)$ & \\
\hline Income & & 0.41 & & 0.76 & & 0.55 & & 0.24 & & 0.53 & & 0.08 & & 0.53 & & 0.16 & & 0.67 \\
\hline 1 to 2 minimum salaries & $12.6(13.6)$ & & $10.5(24.6)$ & & $24.1(18.4)$ & & $49.8(24.0)$ & & $40.0(25.1)$ & & $35.0(18.3)$ & & $26.9(37.7)$ & & $48.0(27.7)$ & & $4.1(0.8)$ & \\
\hline 2 to 3 minimum salaries & $11.4(9.8)$ & & $3.5(9.4)$ & & $16.5(11.7)$ & & $63.7(20.1)$ & & $33.5(26.2)$ & & $51.7(26.4)$ & & $9.5(25.1)$ & & $55.4(25.9)$ & & $4.0(1.1)$ & \\
\hline More than 3 minimum salaries & $22.0(25.6)$ & & $10.0(22.3)$ & & $26.9(25.2)$ & & $63.2(17.5)$ & & $51.0(33.6)$ & & $55.0(36.0)$ & & $26.6(43.4)$ & & $72.8(18.6)$ & & $3.8(1.3)$ & \\
\hline
\end{tabular}


Table 7 - Variables associated with quality of life, in the nine scores that make up the final SF-36: mean score and statistical significance ( $p$-value), 2011.

\begin{tabular}{|c|c|c|c|c|c|c|c|c|c|c|c|c|c|c|c|c|c|c|}
\hline \multirow{2}{*}{ Variáveis } & \multicolumn{2}{|c|}{ Function } & \multicolumn{2}{|c|}{ Physical } & \multicolumn{2}{|l|}{ Pain } & \multicolumn{2}{|l|}{ Health } & \multicolumn{2}{|l|}{ Vitality } & \multicolumn{2}{|l|}{ Social } & \multicolumn{2}{|c|}{ Emotional } & \multicolumn{2}{|l|}{ Mental } & \multicolumn{2}{|l|}{ Final } \\
\hline & Mean (sd) & $\mathbf{p}$ & Mean (sd) & $\mathbf{p}$ & Mean (sd) & $\mathbf{p}$ & Mean (sd) & $\mathbf{p}$ & Mean (sd) & $\mathbf{p}$ & Mean (sd) & $\mathbf{p}$ & Mean (sd) & $\mathbf{p}$ & Mean (sd) & $\mathbf{p}$ & Mean (sd) & p \\
\hline Age & & 0.79 & & 0.69 & & 0.92 & & 0.54 & & 0.96 & & 0.19 & & 0.93 & & 0.27 & & 0.76 \\
\hline From 20 to 60 years & $54.5(26.7)$ & & $50.0(42.9)$ & & $62.9(23.9)$ & & $69.6(23.1)$ & & $70.0(24.4)$ & & $70.3(26.5)$ & & $65.2(37.4)$ & & $78.5(19.1)$ & & $1.5(0.7)$ & \\
\hline From 61 to 99 years & $52.1(29.0)$ & & $44.6(36.9)$ & & $62.0(26.9)$ & & $74.2(21.1)$ & & $69.6(16.2)$ & & $81.2(20.6)$ & & $64.2(38.0)$ & & $84.8(12.5)$ & & $1.43(0.6)$ & \\
\hline Ethnicity & & 0.64 & & 0.45 & & 0.02 & & 0.33 & & 0.20 & & 0.29 & & 0.15 & & 0.06 & & 0.23 \\
\hline White & $51.1(28.5)$ & & $44.3(40.7)$ & & $55.1(27.7)$ & & $67.3(25.6)$ & & $65.6(26.1)$ & & $69.8(28.7)$ & & $72.7(36.5)$ & & $75.8(19.5)$ & & $1.5(0.7)$ & \\
\hline Others & $57.1(25.8)$ & & $53.1(40.6)$ & & $72.8(15.5)$ & & $76.7(15.8)$ & & $75.6(11.3)$ & & $80.4(17.0)$ & & $54.1(36.2)$ & & $87.7(10.0)$ & & $1.3(0.6)$ & \\
\hline Retired & & 0.40 & & 0.53 & & 0.51 & & 0.24 & & 0.26 & & 0.13 & & 0.83 & & 0.10 & & 0.11 \\
\hline Yes & $58.8(23.1)$ & & $42.3(37.3)$ & & $58.9(27.3)$ & & $77.2(20.9)$ & & $75.3(18.7)$ & & $82.6(22.5)$ & & $66.6(30.4)$ & & $87.0(12.4)$ & & $1.2(0.4)$ & \\
\hline No & $51.0(29.2)$ & & $51.0(42.3)$ & & $64.5(23.6)$ & & $68.2(22.6)$ & & $67.0(22.6)$ & & $70.0(25.2)$ & & $63.9(40.7)$ & & $77.6(18.5)$ & & $1.6(0.7)$ & \\
\hline Needing help & & 0.74 & & 0.10 & & 0.69 & & 0.94 & & 0.55 & & 0.56 & & 0.45 & & 0.85 & & 0.57 \\
\hline Yes & $52.8(28.5)$ & & $53.3(40.3)$ & & $61.7(26.4)$ & & $70.8(22.5)$ & & $68.5(22.3)$ & & $72.9(25.6)$ & & $67.7(38.6)$ & & $80.2(17.2)$ & & $1.5(0.6)$ & \\
\hline No & $56.8(23.1)$ & & $28.1(36.4)$ & & $66.0(18.0)$ & & $73.0(22.6)$ & & $75.0(18.5)$ & & $79.6(22.0)$ & & $54.1(30.5)$ & & $83.0(17.8)$ & & $1.38(0.7)$ & \\
\hline Receiving benefit & & 0.60 & & 0.71 & & 0.93 & & 0.79 & & 0.39 & & 0.33 & & 0.89 & & 0.66 & & 0.85 \\
\hline Yes & $58.5(29.6)$ & & $42.8(44.9)$ & & $63.2(23.6)$ & & $69.2(22.4)$ & & $63.5(23.5)$ & & $66.0(22.4)$ & & $66.6(38.4)$ & & $78.2(15.8)$ & & $1.4(0.7)$ & \\
\hline No & $52.5(27.1)$ & & $49.1(40.0)$ & & $62.4(25.3)$ & & $71.7(22.5)$ & & $71.2(21.1)$ & & $76.2(25.2)$ & & $64.5(37.4)$ & & $81.4(17.6)$ & & $1.4(0.6)$ & \\
\hline Income & & 0.17 & & 0.93 & & 0.15 & & 0.76 & & 0.96 & & 0.51 & & 0.86 & & 0.66 & & 0.62 \\
\hline 1 to 2 minimum salaries & $56.1(24.7)$ & & $49.0(41.5)$ & & $66.3(24.2)$ & & $70.1(22.9)$ & & $69.2(23.2)$ & & $71.1(25.9)$ & & $64.1(37.6)$ & & $80.3(18.4)$ & & $1.5(0.7)$ & \\
\hline 2 to 3 minimum salaries & $37.1(36.6)$ & & $42.8(42.6)$ & & $46.1(25.0)$ & & $77.0(19.3)$ & & $70.7(18.1)$ & & $82.1(17.4)$ & & $71.4(35.6)$ & & 85.7 (13.2) & & $1.5(0.5)$ & \\
\hline More than 3 minimum salaries & $64.0(19.4)$ & & $50.0(39.5)$ & & $66.2(21.8)$ & & $69.6(25.5)$ & & $72.0(20.1)$ & & $80.0(28.7)$ & & $59.9(43.4)$ & & $76.8(16.3)$ & & $1.2(0.4)$ & \\
\hline
\end{tabular}

HHS and individual perception shown though the degree of satisfaction with the procedure. This subgroup was composed of male individuals of productive age who showed the characteristic of apparently seeking social security compensation and/or claiming an unreal situation of work disability, despite their satisfactory level of rehabilitation and the similarity of their patterns of clinical and radiological parameters to those of the other patients evaluated. These paradoxical data were labeled "social security compensation bias", as shown by comparing the good results from the specific clinical-radiographic evaluation and the high scores of the HHS, with the responses to the structured quality-of-life questionnaire, which were at the lower limits, in contrast with other individuals presenting similar conditions. This was an unforeseen variable, with an apparent social and pecuniary motivation, which may have had a strong influence at the time of measuring the results, with the potential to substantially change them, depending on the profile of the population under analysis, thereby confounding the observer. Through using multiple tools in the evaluation, it became possible to identify this group and better comprehend and interpret the results in our study.

In the literature worldwide, it can be seen that quality-of-life indicators are increasingly being used in association with the traditional clinical evaluation instruments $^{(20,22)}$. Orthopedic surgeons now tend to include, in their therapeutic decision-making process, not only the clinical and radiological findings but also the health-related quality-of-life context, thus placing value both on general quality-of-life outcomes and outcomes according to domains, functional capacity, pain and personal satisfaction ${ }^{(9)}$. These assessment instruments have been shown to be valuable in determining not only individuals' real health situation and disease manifestations, but also the best time for an operation, which may thus be postponed until social or psychological issues have firstly been attended to and equilibrated. Through this, consequently, surgical conditions that are more appropriate or, conversely, more prioritized in other situations of particular importance may be provided. Ayers and Ring ${ }^{(23)}$ highlighted that patients with impaired emotional health can and should be identified before the operation through applying instruments such as the SF-36, and that since this group tends not to attain the degree of satisfaction and functional evolution expected, these individuals would benefit from a special support strategy. These authors ${ }^{(23)}$ also emphasized that the results from surgical procedures are clearly better when these individuals received emotional and social support, and that patients wish to be seen as people and not as diseases. They noted that the complementary nature of these instruments was evident: they did not replace any clinical or radiographic assessment or specific functional scores but, rather, interacted with them ${ }^{(19)}$. Health-related quality-of-life measurements may also help in determining patients' motivations and expectations regarding total joint replacement, and in following up and measuring patient satisfaction, both 
separately and in association with other types of questionnaires and investigations ${ }^{(24-26)}$. Despite the homogeneity of the cohort in relation to the different variables analyzed, the limitations of the study relating to sample size need to be considered. However, the results from the cohort studied are comparable with those from multicenter studies with large numbers of individuals, with regard to the statistical significance of the evolution achieved in the SF-36 domains and in the specific clinical-functional indicators measured using the $\mathrm{HHS}^{(5)}$.

No consensus or usage pattern has yet been reached regarding the most appropriate scale for measuring health-related quality of life. It is a challenge to understand the literature, given the different methods proposed, the variations in the scores and presentation of these methods, the ways of interpreting them and, especially, the way of selecting the most appropriate score for each population. It also needs to be taken into consideration that patients' own cooperation during long evaluations and questionnaires may be problematic ${ }^{(27)}$. In the cohort studied here, this latter point was prioritized, given the subjects' low schooling level (10.5\% illiterate), which reflected the reality of the Brazilian population in ge- neral, such that in many cases, assistance and technical support is needed in filling out questionnaires.

\section{CONCLUSIONS}

This study demonstrated that there was a significant improvement in the health-related quality of life among patients affected by osteoarthrosis of different etiologies who underwent total hip arthroplasty, over the short-term follow-up.

The results obtained indicate that the SF-36 is useful as a complementary method for evaluating patients undergoing total hip replacement arthroplasty, especially regarding social and psychological issues. Use of this method, in conjunction with specific instruments such as the HHS and traditional clinical-radiological evaluation, was shown to be valuable for making measurements of greater precision regarding these individuals' postoperative satisfaction levels and the observed changes in physical and mental health obtained through the medical intervention, and in identifying the biases and factors that influence both objective and subjective manifestations or perceptions among these individuals regarding their pre and postoperative conditions.

\section{REFERENCES}

1. Quintana JM, Aróstegui I, Azkarate J, Goenaga JI, Elexpe X, Letona J, et al. Evaluation of explicit criteria for total hip joint replacement. J Clin Epidemiol. 2000;53(12):1200-8

2. The World Health Organization Quality of Life Assessment (WHOQOL): development and general psychometric properties. Soc Sci Med. 1998;46(12):1569-85.

3. Ahmad MA, Xypnitos FN, Giannoudis PV. Measuring hip outcomes: common scales and checklists. Injury. 2011;42(3):259-64.

4. Xu M, Garbuz DS, Kuramoto L, Sobolev B. Classifying health-related quality of life outcomes of total hip arthroplasty. BMC Musculoskelet Disord. 2005;6:48.

5. Quintana JM, Escobar A, Arostegui I, Bilbao A, Azkarate J, Goenaga JI, et al. Health-related quality of life and appropriateness of knee or hip joint replacement. Arch Intern Med. 2006;166(2):220-6.

6. Arden NK, Kiran A, Judge A, Biant LC, Javaid MK, Murray DW, et al. What is a good patient reported outcome after total hip replacement? Osteoarthritis Cartilage. 2011;19(2):155-62.

7. Ackerman IN, Graves SE, Wicks IP, Bennell KL, Osborne RH. Severely compromised quality of life in women and those of lower socioeconomic status waiting for joint replacement surgery. Arthritis Rheum. 2005;53(5):653-8.

8. Kellgren JH, Lawrence JS. Radiological assessment of osteoarthrosis. Ann Rheum Dis. 1957;16(4):494-502.

9. Guimaraes RP, Alves DPL, Silva GB, Bittar ST, Ono NK, Honda E, et al. Tradução e adaptação Transcultural do instrumento de avaliação do quadril "Harris Hip Score". Acta Ortop Bras. 2010;18(3):142-7.

10. Ciconelli RM, Ferraz MB, Santos W, Meinão I, Quaresma MR. Tradução para a língua portuguesa e validação do questionário genérico de avaliação de qualidade de vida SF-36 (Brasil SF-36). Rev Bras Reumatol. 1999;39(3):143-50.

11. Patel AA. Donegan D, Albert T. O questionário short-form 36. J Am Acad Orthop Surg. 2007;5(5):193-201. (Edição Brasileira).

12. De Girolamo G, Rucci P, Scocco P, Becchi A, Coppa F, D'Addario A, et al. Quality of life evaluation: validity of short-WHOQOL. Epidemiol Psichiatr Soc. 2000;9(1):45-55.

13. Ware JE Jr, Keller SD, Gandek B, Brazier JE, Sullivan M. Evaluating translations of health status questionnaires. Methods from the IQOLA project. International Quality of Life Assessment. Int J Technol Assess Health Care. 1995;11(3):525-51.

14. Apolone G, Cifani S, Mosconi P. SF-36 health questionnaire. Translation and validity of Italian version: IQOLA project results. Medic. 1997;2:86-94.

15. Apolone G, Mosconi P, Ware JE. SF-36 health questionnaire. Manual for use and guide to interpreting the results. Milan: Guerini \& Associati; 1997

16. McGrory BJ, Shinar AA, Freiberg AA, Harris WH. Enhancement of the value of hip questionnaires by telephone follow-up evaluation. J Arthroplasty. 1997;12(3):340-3.

17. Ostendorf M, van Stel HF, Buskens E, Schrijvers AJ, Marting LN, Verbout AJ, et al. Patient-reported outcome in total hip replacement. A comparison of five instruments of health status. J Bone Joint Surg Br. 2004;86(6):801-8.

18. Tellini A, Ciccone V, Blonna D, Rossi R, Marmotti A, Castoldi F. Quality of life evaluation in patients affected by osteoarthritis secondary to congenital hip dysplasia after total hip replacement. J Orthop Traumatol. 2008;9(3):155-8.

19. McGuigan FX, Hozack WJ, Moriarty L, Eng K, Rothman RH. Predicting qualityof-life outcomes following total joint arthroplasty. Limitations of the SF-36 Health Status Questionnaire. J Arthroplasty. 1995;10(6):742-7.

20. Lieberman JR, Dorey F, Shekelle P, Schumacher L, Kilgus DJ, Thomas BJ, et al. Outcome after total hip arthroplasty. Comparison of a traditional disease-specific and a quality-of-life measurement of outcome. J Arthroplasty. 1997;12(6):639-45.

21. Laupacis $A$, Bourne $R$, Rorabeck $C$, Feeny D, Wong $C$, Tugwell $P$, et.al. The effect of elective total hip replacement on health-related quality of life. J Bone Joint Surg Am. 1993;75(11):1619-26.

22. Chiu HC, Mau LW, Hsu YC, Chang JK. Postoperative 6-month and 1-year evaluation of health-related quality of life in total hip replacement patients. J Formos Med Assoc. 2001;100(7):461-5.

23. Ayers DC, Ring DC. Patients' emotional health plays an important role in functional results. Orthopaedics Today [internet]. 2011 Jun [cited 2011 jun. 10]. Available from: http://www.orthosupersite.com/view.aspx?rid=84493\#perspective.

24. Dawson J, Linsell L, Zondervan K, Rose P, Randall T, Carr A, et al. Epidemiology of hip and knee pain and its impact on overall health status in older adults. Rheumatology (Oxford). 2004;43(4):497-504.

25. Kelly KD, Voaklander DC, Johnston DW, Newman SC, Suarez-Almazor ME. Change in pain and function while waiting for major joint arthroplasty. J Arthroplasty. 2001;16(3):351-9.

26. Padua R, Romanini E, Gillio A, Bondì R, Ceccarelli E, Campi S, et al. Health-related quality of life after hip replacement. J Orthop Traumatol. 2005;6(1):10-14.

27. Singh J, Sloan JA, Johanson NA. Desafios com a avaliação da qualidade de vida relacionada à saúde em pacientes com artroplastia: problemas e soluções. J Am Acad Orthop Surg. 2010;18:72-82. (Edição Brasileira). 